\title{
TEMPERANTIA Y CONTINENTIA EN EL PENSAMIENTO ARISTOTÉLICO DE ALFONSO DE CARTAGENA (CON UN BREVE EXCURSO ACERCA DE LA 'MANTENENÇIA' RUIZIANA)'
}

\author{
Ángel Escobar \\ Universidad de Zaragoza \\ aescobar@unizar.es
}

\begin{abstract}
Alfonso de Cartagena enumera y define en su Memoriale virtutum (1422) once virtudes morales (I 8), añadiendo finalmente una breve consideración en torno a la verecundia (II 26-27). Se ocupa de la temperantia (gr. $\sigma \omega \varphi \rho \circ \sigma u ́ v \eta)$, tercera virtud de su enumeración y «cardinal» tanto en la tradición pagana

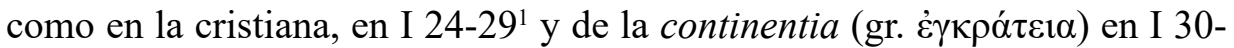
$35^{2}$, en cuanto «cuasivirtud» íntimamente ligada a la anterior (ya que ambas afectan a los placeres del tacto ${ }^{3}$ y cuya ausencia es vicio o defecto que debe rehuirse al igual que la malitia y la bestialitas (Mem. I 30, de acuerdo con lo expresado en la $E N$ al comienzo de su libro VII, 1145a15-17). Desde una optimista perspectiva, Cartagena consideraba que, tras su detallada exposición, cada uno podría juzgar con conocimiento de causa acerca de su propia condición moral: «[...] poterit unusquisque cognoscere et judicare seipsum et discernere an sit temperatus vel intemperatus, continens vel incontinens,
\end{abstract}

\footnotetext{
* Este trabajo se publica en colaboración con el proyecto de investigación Alfonso de Cartagena. Obras Completas FFI 2014-55902-P y FFI 2017-84858-P (MINECO y MICINN, Gobierno de España).

${ }^{1}$ Basados en Tomás de Aquino, Sententia libri ethicorum [= Sent.] III 19-22, donde se parafrasea la Ética a Nicómaco $[=E N]$ 1117b23-1119b18 (ed. de Bekker, por la que siempre citamos).

${ }^{2}$ Según ordenación diferente de la adoptada en Sent. (VII 1-14, sobre la base de EN 1145a15-1154b34).

${ }^{3} \mathrm{Cfr}$, respectivamente, Mem. I 30, p. 96: «Quia temperancie de qua diximus videtur adhaerere continencia, $[\ldots] » ;$ I 32, p. 102: «Nam continencia et incontinencia est in eadem materia et circa easdem delectaciones circa quas est temperancia et intemperancia. [...] in delectacionibus tactus, quia circa illas proprie et simpliciter consistunt continencia et incontinencia»; II 1, p. 109: «[...] sicut temperancia moderatur concupiscencias delectacionum tactus, [...]»; citamos el Memoriale por la edición en prensa a la que nos han dado amable acceso M. Morrás y J. Lawrance.
} 
perseverativus vel mollis; et, si incontinens, an prevolativus vel debilis») (I 35).

El recurso constante por parte del autor a la Sententia libri ethicorum de Tomás de Aquino (de c. 1271-1272, cuando este escribía asimismo la segunda parte de la Summa theologica) no sorprende si se tiene en cuenta que la interpretación propuesta por el dominico - continuador de las pioneras enseñanzas de Alberto Magno en Colonia, a mediados del XIII- se había impuesto en el ámbito de la enseñanza teológica desde el siglo XIV, tras un periodo de cierto escrutinio dentro del ámbito universitario ${ }^{4}$. La deuda de Cartagena es abiertamente reconocida en el prólogo del Memoriale, donde declara que su labor solo pretende contribuir a «trabar» el texto de sus modelos exegéticos -«Tomás sobre todo»-y a facilitar así su cabal comprensión (pról., p. 50: «ad ordinis connexionem vel ad planiorem intelligenciam»).

\section{Inclinatio frente a razón, voluntad y costumbre}

El debate en torno al influjo de la naturaleza de cada individuo sobre su capacidad de elección -ya sea en el ámbito de lo vital y moral o en otros menos graves, como el del mero gusto- se planteó en la Antigüedad y desde entonces no dejó de suscitarse. Uno de los vocablos empleados para referirse al problema fue el viejo término latino inclinatio (y afines), entendido como la predisposición de cada animus, espontánea en principio, que hace a este tender hacia una virtud -ya sea generalizada, como el deseo de $\operatorname{saber}^{5}$, o

\footnotetext{
${ }^{4}$ Como muestran por ejemplo, en terreno dominico, el Compendium ethicorum de Corrado d'Ascoli o la Summa de virtutibus di Guido Vernani; dentro del ámbito franciscano destaca la obra del Doctor moralis, Gerardus Odonis (Scriptum super libros Ethicorum o Sententia et expositio cum quaestionibus super libros Ethicorum), fuente de autores tan influyentes como Juan Buridano; según señaló Camarin Porter ( "Gerald Odonis' commentary on the Ethics: a discussion of the manuscripts and general survey», en Vivarium, 47 [2009], pp. 241-294, en p. 244), la tradición franciscana se caracterizaba, en general, por preservar el libre albedrío y la posibilidad de culpa frente a la subordinación tomista de la voluntad al intelecto.

${ }^{5}$ Según se expresa en la carta dirigida c. 1440-1444 a Fernández de Velasco (ed. de Lawrance): «Sciendi desiderium [...] addeo hominibus conaturale est, ut omnes ex impulsu nature scire desiderent, neque quisquam tam ebetis ingenii repertus est, qui ad sciendum cum potest non inclinetur»; sobre la $\mathrm{cu}$ riositas como extremo opuesto cabría aludir a la versión de la epístola sobre las artes liberales de Séneca (c. 1434; cfr. Juan Miguel Valero Moreno, «Las Artes liberales de Alonso de Cartagena: los manuscritos salmantinos y el tipo $\alpha$ », en Modelos intelectuales, nuevos textos y nuevos lectores en el siglo XV. Contextos literarios, cortesanos y administrativos. Primera entrega, present. y dir. de Pedro Cátedra, Salamanca, SEMYR, 2012, pp. 135-213, en pp. 188-189, líns. 388-395: «E por çierto tan bien es destempramiento e desordenança querer saber más de lo que basta. E demás desto puedo dezir que el studio demasiado de las artes liberales faze a los omnes ser renzellosos e parleros e tales que non saben guardar tiempo e que se tienen en mucho. ¿E sabes por qué estos tales non aprenden lo nesçessario? Yo te lo diré: porque aprendieron lo superfluo»; en clave bíblica cabe remitir a Eccl. 7, 17, ed. Vulg.: «noli esse iustus multum neque plus sapias quam necesse est ne obstupescas»)).
} 
particular6 - o más bien hacia un vicio (Mem. II 15, p. 131: «[...] virtus precipue ordinatur ut reprimantur humane inclinaciones ad malum; $\left.[\ldots]\rangle^{7}\right)$.

Consecuentemente, ya en el marco de su discusión previa acerca de la prudentia, cualidad primera y esencial, Cartagena distingue dos tipos de virtud (virtus naturalis y virtus moralis) e indica que la primera de ellas es una inclinatio o dispositio que cada uno posee a partir de su naturaleza particular (a natura propria) y que no puede definirse en rigor como una virtus ( $E N$ 1144a20-22), ya que también se halla en los niños, seres carentes de ratio, y en los animales (EN 1144b8-9), y ya que, si se usa sin discernimiento o límite (discretio, modus), puede llegar a producir daños en lugar de bienes (Mem. I 7, p. 58):

Virtus naturalis est illa inclinacio quam quis habet a natura propria; sunt enim aliqui qui inclinantur ad justiciam, alii ad fortitudinem vel ad liberalitatem vel ad abstinenciam. Ista ergo disposicio dicitur virtus naturalis, sed non est proprie virtus, quod patet ex eo quod interdum est in pueris qui carent judicio racionis et in bestiis, sicut leo naturaliter est fortis; et si iste inclinaciones non regantur per discretionem possent inducere maxima dampna, sicut si aliquis velox ad currendum curreret clausis occulis posset enormiter ledi. Sic in moralibus si inclinatus ad liberalitatem expendit sua sine discrecione perdet substanciam suam, et si inclinatus ad abstinenciam abstinet immoderate perdet corpus.

Cartagena partía para su definición de la Sententia de Tomás de Aquino, a propósito de los naturales habitus o inclinationes que, para ir acompañados de bondad, necesitan el concurso del intellectus (lib. VI, lect. 11, n. 4-5):

Unde secundum hoc dicit hic Philosophus quosdam esse naturaliter fortes vel iustos: et tamen requiritur in his qui naturaliter sunt tales aliquid aliud quod sit principaliter bonum, ad hoc quod praedictae virtutes secundum perfectiorem

\footnotetext{
${ }^{6} \mathrm{Cfr} . \mathrm{Mem} . \mathrm{I}$ 7, p. 59: «[...] videmus communiter aliquos inclinari ad liberalitatem et non ad castitatem vel econtra, et sic in aliis virtutibus»; I 22, p. 85: «Operatur enim fortis ex inclinacione proprii habitus. Ideo fortitudo vera maxime apparet in actibus repentinis, ut diximus; nam in aliis ubi potest precedere deliberacio potest homo aliqua contra inclinacionem animi operari, sed in hiis que repente accidunt opportet operari ex habitu interiori. Ideo facilius et manifestius apparet si est fortis vel ne cum terribilia subito occurrunt»; similar énfasis sobre la manifestación repentina de la inclinatio se observa en el Duodenarium: cfr. El Duodenarium (c. 1442) de Alfonso de Cartagena. Cultura castellana y letras latinas en un proyecto inconcluso, estudio, ed. y tr. de Luis Fernández Gallardo y Teresa Jiménez Calvente, Córdoba, Almuzara, 2015, en IV 5, p. 400: ex subitanea operacione.

${ }^{7} \mathrm{Cfr}$. por ejemplo II 5, p. 115: «[...] illud ad quod homo naturaliter inclinatur non de facili tollitur ab eo; magis autem inclinatur homo ad illiberalitatem quam ad prodigalitatem,[...]. Difficiliter ergo curatur illiberalitas quia est quodammodo naturalis»; 117, II 19, p. 139, etc.
} 
modum in nobis existant, quia praedicti naturales habitus sive inclinationes etiam pueris et bestiis insunt, sicut leo naturaliter est fortis et liberalis, sed tamen huiusmodi habitus naturales videntur esse nocivi nisi adsit discretio intellectus. Et videtur, quod sicut in motu corporali si corpus fortiter moveatur absque visu dirigente, accidit, quod id quod movetur impingat et fortiter laedatur, ita etiam est et hic; si enim aliquis habeat fortem inclinationem ad opus alicuius virtutis moralis et non adhibeat discretionem, accidet gravis laesio, vel corporis proprii, sicut in eo qui inclinatur ad abstinentiam sine discretione, vel rerum exteriorum, si inclinetur ad liberalitatem: et simile est in aliis virtutibus. Sed si huiusmodi inclinatio coaccipiat in operando intellectum, ut scilicet cum discretione operetur, tunc multum differet secundum excellentiam bonitatis, et habitus, qui erit similis tali operationi cum discretione factae, erit proprie et perfecte virtus, quae est moralis $\rangle^{8}$.

Como suele hacer, Cartagena selecciona, matiza y a veces amplifica ligeramente; así por ejemplo al aclarar lo referente a la liberalitas («prodigalidad»), que, de ser extrema y mal orientada, hace perder cuanto se posee (substantia: cfr. Prov. 29, 3; Lc. 11, 13; Mem. II 1, p. 109), o al introducir el concepto de 'razón' (los niños carent judicio racionis ${ }^{9}$ ), clave de buena parte de su propedéutica filosófica, frente al de intellectus, muy característico del pensamiento tomista más genuino pero don de inferior valor en su escala, aparentemente, que la scientia o que la sapientia que Cartagena atribuye al 'divino' Sócrates (Mem. I 4, p. 55; cfr. EN 1141a18-2010). La inferioridad del intellectus parece apuntarse de nuevo en el Duodenarium de c. 1422, al aludirse a su posible embotamiento momentáneo (por ejemplo a causa de un despertar brusco, pues una «subita excitatio sompni-según IV 5, p. 400-intellectu aliqualiter ebetato ad sensibilia vehemencius inclinat»; el argumento se retomará en IV 7, p. 406).

Cuando existe en el individuo una predisposición natural, solo la ratio (es decir, el juicio que debe imponerse a la concupiscentia, gr. غ̇ $\pi \imath v \mu i ́ \alpha)$ puede definir la auténtica virtud o, por el contrario, conducir al peor de los vicios,

${ }^{8}$ Citamos por la ed. Leonina (I-II, 1969), también accesible en la versión electrónica aparecida en el Corpus Thomisticum de Enrique Alarcón. Enlace: <http://www.corpusthomisticum.org/ctc0101.html > [Consulta: $1 / 04 / 2018]$.

${ }^{9}$ Cabe comparar las palabras de la casta Susana a José en el Duodenarium, IV 11, p. 418: «[...] adolescentis etatis carnales impetus, qui vehementissimi esse solent, racionis imperio subiecisti».

${ }^{10} C f$ r., previamente, p. 54: «Intellectuales virtutes sunt quinque, videlicet sapiencia, sciencia, intellectus, prudencia, et ars, sicut sunt quinque modi per quos anima dicit verum» (frente a Sent. VI 3, 2: «Sunt autem quinque numero quibus anima semper dicit verum vel affirmando vel negando: scilicet ars, scientia, prudentia, sapientia et intellectus»; Cartagena volverá sobre el asunto en el Orac., cap. VII, p. 69, ed. de Silvia González-Quevedo, El «Oracional» de Alonso de Cartagena: edición crítica (comparación del manuscrito 160 de Santander y el incunable de Murcia), Chapel Hill y Valencia, Albatros, 1983). 
que es el que se produce tras mediar reflexión (pues la concupiscencia siempre es prospectiva o de bono futuro: I 26) y el que, de haber mediado un mínimo esfuerzo, habría podido evitarse (ibíd.: «[...] tanto aliquod vicium est magis exprobrabile quanto facilius vitari potest [...]. Ideo intemperancia vituperabilior est, cum facilius vitari possit»). Así, quien carece de templanza ante una pequeña o nula concupiscencia es más reprobable que el incontinente (I 32, p. 102):

Est autem intemperatus deterior et vituperabilior quam incontinens, quia persequitur superfluas delectaciones et fugit moderatas tristicias non propter concupiscenciam, quia illam non sentit vel saltem sentit remisse, sed ex perversa eleccione racionis; incontinens vero hoc facit propter concupiscenciam, sed qui sine concupiscencia vel cum parva concupiscencia peccat multo amplius peccaret si vehementem passionem sentiret; ideo vituperabilior et pejor est.

Algo similar se había apuntado ya en I 21, siguiendo el hilo argumental aristotélico de EN 1116b27-1117a9, a propósito de la fortitudo, una virtud que, frente a lo que ocurre en el caso de los animales, debe regirse por la razón y no por la mera pasión:

[...] unde et Homerus dicebat, «virtutem immitte furori», hoc est ut furor regatur per virtutem. Nam virtus non debet servire furori, sed furor virtuti. Ira enim debet preveniri et regi per prudentem eleccionem et deliberatum et maturum judicium racionis. Bestie autem ex solo impetu furoris ducuntur; ideo non dicuntur fortes, sicut nec asini sunt fortes quia percussi a pascuis non recedunt, nec adulteri qui propter concupiscenciam venereorum aliqua periculosa agrediuntur. Isti vero qui ex furore ire operantur querunt aliquem finem, scilicet vindictam; irati enim solent vindictam desiderare, et punientes delectantur et quiescunt. Pugnaces ergo possent dici, sed fortes non, quia ex passione ducuntur, non a racione.

También en este caso seguía Cartagena muy de cerca el texto de la Sententia (III 17, 2-6), pero matizando a su gusto, por ejemplo para aludir a la necesidad de que la ira, regia inclinación, responda -lejos de ser involuntaria- a un «deliberatum et maturum judicium racionis».

La oposición entre concupiscentia y ratio es recurrente en toda la sección del Memoriale que estamos analizando. Así ocurre en lo concerniente a la templanza: el intemperatus, frente a lo que ocurre en el caso del incontinens, persigue los placeres de manera consciente (ex eleccione), si bien su elección «non regitur racione, sed ducitur a concupiscencia ut eligat delectabilia» (I 
26, copiando Sent. III 21, 3); por el contrario, el temperatus desea lo necesario, sin exceder la mensura racionis (I 27; cfr. Sent. III 21, 7) o, como habría apostillado el Arcipreste, la 'mesura' - más que privación- que caracteriza al cuerdo (74c). El pueril acoso de la concupiscencia debet regi per racionem (I 29), ya que el apetito de placer es insaciable y ya que los placeres, a su vez, suelen dificultar la reflexión racional («sepe impediunt hominis cogitacionem sive raciocinacionem»), de modo que, en formulación también copiada de Tomás, «quanto autem magis remanet raciocinacio in homine, tanto concupiscencia minus potest dominari» (cfr. Sent. III 22, 12). El hombre templado no debe desear nada que su razón no pueda controlar: «non concupiscat rem que concupisci non debet secundum racionem [...] debet vis concupiscibilis consonare racioni; [...] concupiscit que opportet et sicut opportet et quando opportet prout ordinat racio» (cfr. Sent. III 22, 13). Cartagena reflejará la misma opinión acerca del placer «deseable» algunos años más tarde (c. 14301434), en su respuesta a Bruni, con insistencia tendente sobre todo a condescender con la incontinencia en cuanto «irracional», frente al vicio consciente de los que llama 'malos sin paliativos' (puri mali ${ }^{11}$ ). También lo hará en sus glosas senecanas, ya mediante formulaciones más generales y alejadas del corsé que le imponía la Sententia:

Por la philosophía sabemos que la temprança manda a los deleites e a algunos aborresçe e a algunos echa de sí e de algunos usa tempradamente quanto cumple a la sanidat. E nunca usa de los deleites por ellos mesmos, mas por otro fin mejor. E sabe que la regla de usar de delectaçión deseable es non tomar della quanto omne quiere, mas quanto deve ${ }^{12}$.

En lo referente a la continencia -habitus laudabilis, pero, en cuanto mero ejercicio de resistencia, no perfecta virtus (Mem. I 31; T. González Rolán, A. Moreno y P. Saquero Suárez, ed. cit., p. 258, 11. 821-825)- las afirmaciones serán comparables: una bona consuetudo permite amoldar la concupiscencia a la razón, ya que no basta con aplicar un saber teórico (scientia), si al final el individuo puede dejarse llevar por el silogismus concupiscencie -que conduce a perseguir el placer frente a lo que se sabe moralmente correcto ( $c f r$. EN 1147a18-b5)- y no por el silogismus racionis (syllogismus temperati, según la Sententia, VII 3, 19), cristianamente ejemplificado por Cartagena (I 31, p. 100):

${ }^{11} C f r$. ed. de Tomás González Rolán, Antonio Moreno Hernández y Pilar Saquero Suárez-Somonte, Humanismo y Teoría de la Traducción en España e Italia en la primera mitad del siglo XV. Edición y estudio de la «Controversia Alphonsiana» (Alfonso de Cartagena vs. L. Bruni y P. Candido Decembrio), Madrid, Ediciones Clásicas, 2000, pp. 258-262, 11. 808-814, 821-825, 830-832, 837-839, 861-862.

${ }^{12}$ Valero Moreno, «Las Artes liberales», ed. cit., p. 186. 
[...] incontinens scit duas proposiciones universales, sed tamen propter passionem concludit sub particulari unius et non atendit particularem alterius, ut in exemplo, dato quod incontinens vellet comedere carnes in aliquo die Quadragesime sine causa legitima, ut sit actus illicitus, iste habet duos silogismos: unus, «Omnis cibus delectabilis est comedendus, cibus carnium est delectabilis, ergo comedendus», et iste est silogismus concupiscencie; alius est, «Omnis cibus illicitus est respuendus, cibus carnium in Quadragesima est illicitus, ergo respuendus», et iste est silogismus racionis.

Según se indica tras el ejemplo (único caso quizá en el que Cartagena parece recurrir a términos lógicos, más frecuentes en la Sententia que parafrasea), el sujeto continente es «permansivus in racione et vincit passionem adherens racioni», sin permitir que un hábito fuerte («sciencia est habitus fortissimus anime») ceda ante otro inferior; deja de serlo si, pese a poseer recta ratio, cede, a causa de la pasión, al placer ilícito que se le ofrece, ya que la continencia no consiste en ser templado (es decir, virtuosamente moderado), sino, según la consabida metáfora platónica del Fedro, en «refrenare concupiscencias propter racionem» (I 33).

Es incontinente tanto quien prescinde de la reflexión-incontinens prevolativus $^{13}$, como suele ser el caso de los colerici vel melancolici (acuti) a causa de su humor predominante, subtilis y frigidus respectivamente ${ }^{14}$ - como, peor aún, quien, pese a recurrir a tal deliberación, termina cediendo (incontinens debilis), a menudo por ser sanguineus oflegmaticus, es decir, de complexión húmeda $\left(\mathrm{I} 33^{15}\right)$. También dentro de la escala de la incontinencia, tanto peor es la caída cuanto menor es la pasión que amenaza («tanto deterior est incontinens quanto a minori passione vincitur»), como ocurre en el caso del mollis, incapaz incluso de soportar la tristeza que le produce un placer ausente, o del ya mencionado incontinens debilis, el cual -como la mítica Medea de

${ }^{13}$ Según el particular derivado de prae- /prevolatio que propone Cartagena, frente al esperado prevolans que ofrecía la traducción de Grosseteste en EN 1116a7 y la Sententia en III 15, 5 o VII 8, 5.

${ }^{14}$ Cfr. Sent. IV 13, 10: «Ad hanc autem speciem irae maxime videntur disponi cholerici propter subtilitatem et velocitatem colerae»; VII 5, 2: «Similiter etiam inter homines, cholericis delectabilia sunt naturaliter frigida quae temperant eorum complexionem, phlegmaticis vero calida»; VII 14, 17: «Et dicit, quod melancholici secundum naturalem dispositionem semper indigent medicina contra tristitias, quia corpus eorum patitur corrosionem quamdam propter siccitatem complexionis. Et ideo habent vehementem appetitum delectationis per quam huiusmodi tristitia repellatur»; el argumento se retomará en Mem. II 19.

${ }^{15}$ Cfr. Sent. VII 7, 18: «Et dicit quod maxime sunt incontinentes secundum incontinentiam quae non refrenatur consilio, quae dicta est praevolatio acuti, idest cholerici et melancholici. Neutri enim expectant rationem consiliantem, sed sequuntur primam phantasiam concupiscibilis. Cholerici quidem propter velocitatem motus colerae, melancolici autem propter vehementiam motus melancholiae accensae, cuius impetum non de facili potest homo ferre. Nam et terra accensa vehementius ardet. E contrario autem est intelligendum, quod sanguinei et phlegmatici habent incontinentiam debilitatis propter humiditatem complexionis, quae non est fortis ad resistendum impressioni». 
Eurípides- «preconsiliatur et audit racionem (expresión usada por Tomás en Sent. VII 6, 2, en relación con la ira), sed tamen sequitur concupiscenciam, et sic videtur magis voluntarie peccare», si bien resulta siempre peor el intemperatus, en cuanto «irrecuperable» («insanabilis, quia peccat ex quadam perversitate racionis ${ }^{16}$ et habet pro presuposito quod est bonum sequi quecumque delectabilia, sive illicita sive licita sint»): comete sus vicios por elección, no como víctima de la pasión («ex eleccione racionis tanquam finem, et non propter passionem sicut incontinens»), y, a causa de su malicia continua, ni ve su error ni siente la necesidad de enmendarlo (I $34^{17}$ ).

Para que exista virtud y su efecto correspondiente se requiere, además de una favorable inclinatio (reflejo, en principio, de la natural intuición del verdadero bien ${ }^{18}$ ), la intervención de la costumbre y de la voluntas, como se observa por ejemplo en el caso de la justicia (I 8, p. 60):

Nam ex justicia causatur in homine quedam inclinacio ad opera justicie; post inclinacionem fiunt opera justa, et ex operacionibus justis redditur homo volens justa et sic efficitur justus. Nec enim ex eo quod quis operetur aliqua opera que videntur justa dicitur justus, sed quando habet jam habitum causatum et constantem in voluntate ad volendum justa ${ }^{19}$.

A razón y voluntad se añadía, por tanto, el factor de la costumbre o reiteración (esa especie de «segunda naturaleza» algo más maleable que la primera: $\left.E N 1152 \mathrm{a} 29-31^{20}\right)$, ya que un proceder de carácter espóradico, inmotivado y

${ }^{16} \mathrm{Cfr}$. Mem. I 33, p. 104: «si racio perverteretur non dicitur incontinens sed intemperatus». Tal perversión de la recta ratio no deja de recordar la que sufre la recta voluntas en términos agustinianos (Civ. XIV 7, 2: «recta itaque voluntas est bonus amor et voluntas perversa malus amor»), analizada en su día por $\mathrm{E}$. Michael Gerli, «Recta voluntas est bonus amor: St. Augustine and the didactic structure of the Libro de buen amor», en Romance Philology, 35 (1982), pp. 500-508.

${ }^{17}$ Cabe comparar el caso de la ira incontinente (Mem. I 32, p. 102: «Et deterior est incontinencia simplex quam incontinencia ire, propter duo: primo, quia iratus non videtur tantum deliberate peccare, nam ex quadam naturali complexione ad hoc sepe adducitur [...]. Incontinens autem in utroque se habet econtra, primo quia melius posset deliberare si vellet, secundo quia dolosior et fraudulentior videtur esse et magis insidiose peccat»). Por supuesto, al duelo entre razón y naturaleza ya se había aludido, en clave literaria, en infinidad de lugares, como por ejemplo en el Libro de buen amor, al afirmarse que «el omne quando peca bien vee que desliza, / mas non se parte ende, ca natura lo enriza» ( $75 \mathrm{~cd}$, Juan Ruiz, Arcipreste de Hita, Libro de buen amor, ed. de Alberto Blecua, Madrid, Cátedra, 1992; cfr. lat. irritat).

${ }^{18}$ Cfr., por ejemplo, Tomás de Aquino, In Physic., I 10, 5: «[...] intellectus hominis quadam naturali inclinatione tendit in veritatem, licet rationem veritatis non percipiat»).

${ }^{19}$ Cfr. EN 1129a6-9, Sent. V 1, 4: «[...] iustitia sit talis habitus per quem tria causantur in homine: primo quidem inclinatio ad opus iustitiae, secundum quam dicitur homo operativus iustorum; secundum est operatio iusta; tertium autem est quod homo velit iusta operari»).

${ }^{20}$ Cfr. Summa Ia-IIae q. 58 a. 1: «Dicitur autem virtus moralis a more, secundum quod mos significat quandam inclinationem naturalem, vel quasi naturalem, ad aliquid agendum. Et huic significationi moris propinqua est alia significatio, qua significat consuetudinem, nam consuetudo quodammodo vertitur in 
casual, no era, en rigor, calificable de virtuoso (lo que entrañaba a su vez una cierta disculpa de los desórdenes de carácter aislado, bien ejemplificados en el monje borracho del milagro berceano, 462d-463a: «pero ovo en cabo de caer en un vicio. / Entró enna bodega un día por ventura» [...]):

Et repeto semper habitum electivum quia hoc est commune omnibus virtutibus moralibus, ut operentur ex habitu et eleccione. Si enim aliquis operaretur unum vel duos vel eciam decem actus virtutum non dicitur virtuosus nisi haberet habitum causatum, hoc est consuetudinem operandi; antiquum namque proverbium est, «una yrundo non facit ver» ${ }^{21}$. Sic unus actus non facit hominem virtuosum, sed quando ex pluribus actibus est acquisitus habitus seu consuetudo, tunc proprie homo dicitur habere virtutem (I 10, p. 63, donde Cartagena sustituye la felicitas de sus fuentes por virtus).

La idea ${ }^{22}$ volverá a aflorar en el Duodenarium (IV 17, p. 440: «ex continuis actibus habitus virtutis adquiritur») y en el Oracional, donde ya se añade la referencia a la gracia («infusión de Dios»; cap. XVII, p. 95), de eficacia superior a la de toda naturaleza.

Por lo demás, voluntad y costumbre - o más bien costumbre y voluntadno dejaban de ser meras secuelas del ejercicio previo de la razón o entendimiento, concepto siempre dominante en el marco casi «trifuncional» de la especulación al respecto -ya en términos agustinianos (De trin. XIV 7, 10)$\mathrm{y}$, de forma muy marcada, en la selección léxica de Cartagena. Se trata de los tres niveles que había de dominar el sapiens, tradicionalmente, para refrenar su predisposición natural hacia el vicio, como bien lo encarnaba desde la Antigüedad la figura de un Sócrates propenso por naturaleza hacia la lujuria, según reflejaba su fisonomía, y cuyo ejemplo mostraba que en realidad toda virtud -como la de la continencia en su caso- era resultado de scientia o

\footnotetext{
naturam, et facit inclinationem similem naturali. [...] Et ideo non omnis virtus dicitur moralis, sed solum illa quae est in vi appetitiva»); Cartagena volverá sobre los electivi habitus en su respuesta a Bruni (ed. de T. González Rolán, A. Moreno y P. Saquero Suárez, ed. cit., pp. 236 y 238, 11. 536-539).

${ }^{21}$ La frase no se extrae de la Sententia (I 10, 12: «Sicut enim una hirundo veniens non demonstrat ver nec una dies temperata, ita etiam nec una operatio semel facta facit hominem felicem, sed quando homo per totam vitam continuat bonam operationem»), sino de la traducción latina de $E N$ 1098a18 por Grosseteste -retomada casi literalmente por Bruni- o de la simple memoria (sobre el pasaje en conjunto cfr. Michele Curnis, «La rondine di Aristotele (EN 1.7.1098a 18 s.). Un celebre proverbio sulla felicità», en Ritorno ad Aristotele, ed. de Amedeo Alessandro Raschieri y Stefano Casarino, Canterano, Aracne, 2017, pp. 49-89, en p. 56, n. 13).

${ }^{22} \mathrm{Cfr}$. Mem. I 26, p. 94: «Vitari vero potest unumquodque vicium per assuetudinem ad contrarium, [...]»; I 31, p. 99: «Ex magna autem consuetudine continencie pervenitur ad virtutem, et ex magno usu incontinencie pervenitur ad maliciam [...] Nam bona consuetudo facit conformari concupiscenciam racioni, mala econtra facit conformari racionem concupiscencie»; etc.
} 
razón ${ }^{23}$, mientras que la actuación sin control lo era de una ignorancia similar a la de los enfermos, los dormidos o los ebrios ${ }^{24}$.

\section{Concupiscentiae communes y propriae}

Las premisas subjetivas expuestas deben combinarse, desde el otro eje, con las derivadas de la existencia de varios tipos de concupiscencia o deseo. Según Aristóteles (EN 1118b8-11, recens. recogn., p. 428 Gauthier), estos

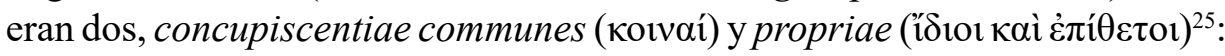
«Concupiscenciarum autem hee quidem communes videntur esse, hee autem proprie et apposite; puta que cibi quidem naturalis, omnis enim concupiscit quando indigens fuerit siccum vel humidum cibum, quandoque autem ambos. Et lectum [scil. coniugalem, s. 1./ marg. Grosseteste, p. 198 Gauthier], inquit Homerus, iuvenis et crescens» [cfr. Il. XXIV 129-131, donde Tetis invita a su afligido hijo Aquiles - para escándalo del puritano gramático Aristarco, que «obelizó» o propuso «atetizar» los versos 130-132- a comer y a entregarse al amor -cosa que parece hacer (v. 676) gracias a Briseida- antes de morir prematuramente].

A ambos tipos de concupiscencia (correspondientes a la natura generis vel speciei y a la complexio o natura individui, respectivamente) se había referido Tomás de Aquino en su Sententia, texto que Cartagena mantendrá, como de costumbre, muy a la vista (III 20, 8-9):

Et dicit, quod concupiscentia cibi in communi est naturalis, utpote consequens totam naturam speciei aut etiam generis. Et inde est, quod omnis homo ad subveniendum indigentiae naturae concupiscit siccum alimentum quod dicitur

${ }^{23}$ De acuerdo con el ratione a se deiecta (sc. vitia) diceret (sc. Socrates) de Cicerón (Tusc. IV 37, 80; cfr. EN 1145b25-27; Sent. III 16, 9 y VI 11, 8, 10, 12, VII 2, 4 y 6, X 14, 8, etc.), siempre sobre el trasfondo de Platón (Protag. 358d) y del propio mecanicismo aristotélico (a afirmación y negación en el ámbito del intelecto le corresponden aceptación o rechazo en el del apetito: EN 1139a21-22); sobre la transmisión de la anécdota, en general, $c f r$. Juan Manuel Cacho Blecua, «Las limitaciones de la fisiognómica: la victoria del sabio (Sócrates e Hipócrates) sobre las inclinaciones naturales», en Estudios de literatura medieval en la Península Ibérica, coord. por Carlos Alvar, San Millán de la Cogolla, Cilengua, 2015, pp. 341-364.

${ }^{24}$ Cfr. EN 1147a15-17, 1147b6-9. A propósito de la «akrasía» como consecuencia o causa de enfermedad, cfr. Sarah Francis, «"Under the influence": the physiology and therapeutics of 'akrasia' in Aristotle's Ethics», en The Classical Quarterly, n. s. 61 (2011), pp. 143-171; cabe comparar Mem. virt. I 31: «Simile est in incontinente, qui licet habeat scienciam universalem, habet tamen habitum ejus ligatum in particulari propter passionem, et presertim in passionibus vehementioribus ut sunt ire et venereorum, que nedum faciunt transmutaciones animales, sed eciam transmutant disposicionem corporalem, et interdum in tantum procedunt quod faciunt aliquos verti in insaniam»; cfr. Sent. VII 3, 15).

${ }^{25}$ Frente a la complejidad de otras taxonomías antiguas, como por ejemplo la de Ps.-Andronico de Rodas en el De passionibus («Concupiscentiae species viginti quinque: ira, furor, cholos [...]», ed. de Gilbert-Thirry, pp. 228-229). 
cibus, vel humidum quod dicitur potus et quandoque utrumque. Sicut etiam Homerus dicit, quod omnis homo tam iuvenis quam crescens, idest adolescens concupiscit lectum in quo requiescat ${ }^{26}$. [...] Et dicit, quod non omnes homines concupiscunt talem vel talem lectum, puta stratum plumis aut pretiosis tegumentis. Similiter etiam non omnes desiderant talem vel talem cibum, puta pretiosum aut delicate paratum; neque etiam omnes idem concupiscunt; sed quidam in talibus, concupiscunt hoc, quidam aliud. Unde huiusmodi concupiscibilia videntur esse nostra, quia scilicet ad ea non inclinamur ex natura, sed potius ex nostra adinventione. Nihil tamen prohibet etiam in his esse aliquid naturale quasi pertinens ad naturam individui licet non pertineat ad naturam generis vel speciei. Videmus enim quod diversa sunt delectabilia diversis, secundum diversas complexiones eorum. Et quibusdam sunt quaedam delectabiliora quam alia indifferenter propter naturalem complexionem eorum.

En la reflexión de Cartagena (I 26) las concupiscencias primeras o communes proceden de la naturaleza y afectan a todos los hombres («a natura omni homini conveniunt»), con dos objetivos: la subsistencia personal (gracias al alimento y la bebida, «cibum et potum ad se sustentandum») y el «descanso» («lectum in quo requiescat», retomando la parcial expresión de Tomás $-\mathrm{y}$ de Alberto Magno- pero sustituyendo antes su «tam iuvenis quam crescens, idest adolescens», derivado de la versión latina, por un realista «tam juvenis quam senex», de acuerdo con la variante de la Ethica vetus -senex como

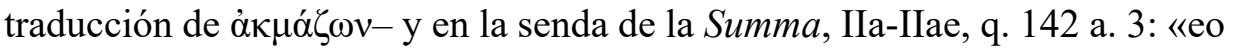
quod delectationes ciborum et venereorum, circa quas est intemperantia, per totam vitam occurrunt, [...]»; que en la elección pueda subyacer una velada referencia al «Aristóteles cabalgado» o similares es inverosímil o, al menos, indemostrable). Por el contrario, las segundas o propriae son de carácter particular e intransferible, no se derivan de la naturaleza común a todos («nam communis natura non inclinat ad hoc, quia non idem placet omnibus $\gg{ }^{27}$ ) sino que dependen de la personalidad de cada individuo («secundum personam concupiscentis») y de su complexionis inclinatio o consideratio (adinventio según la peculiar terminología tomada del de Aquino):

hee concupiscencie habent interdum aliquid naturale secundum personam concupiscentis, ut cum aliquis non solum ex adinvencione sua sed ex quadam inclinacione complexionis desiderat $[\ldots]$ Inest ergo in hiis aliquando aliquid

${ }^{26}$ Frente a la también correcta interpretación de Averroes ( $c f r$. ed. de Leon., app. ad loc.: «et adolescens et perfectus desyderat cum eis [sc. cibis] coitum»).

${ }^{27}$ Cfr. Pínd., Pyth. X 60, Lucr. II 258: «quo ducit quemque uoluptas»; Virg., Ecl. II 65: «trahit sua quemque uoluptas»; etc. 
naturale secundum consideracionem persone concupiscentis, non tamen naturale commune quod communiter conveniat toti generi humano.

Y, mientras que en el caso de las concupiscencias 'comunes' son pocos los que pecan y por exceso («quis plus accipit quam natura requirat»), por ejemplo cuando existe furor ventris (gr. $\gamma \alpha \sigma \tau \rho \mu \alpha \rho \gamma i \alpha$ ), en el caso de las 'propias' son muchos los que lo hacen y, además, de muy variadas maneras ${ }^{28}$.

Sin referencia aparente al texto aristotélico antes citado, a los placeres corporales de carácter «común» (entendido como «vil») se aludirá en el Duodenarium (IV 17, ed. cit., p. 442):

$\mathrm{O}$ infelicem principem, cuius animum non vehemencius iusti belli labores quam corporee voluptates delectant! Illa enim delectacio propria regnancium est, hec autem eciam vilium personarum comunis [...] comunibus voluptatibus uti potuisses, omnia tamen eleuato corde transcendens regias virtutes comunibus cumulasti.

Tanto en el caso de la incontinentia como en el de la malitia, el individuo se ve afectado previamente por una perturbación de la commensuracio affeccionum similar a la que, al romperse la humorum armonia produce la enfermedad corporal (I 30, p. 96, sobre la base de Sent. VII 1, 4):

[...] ad quodcumque bonum opus operandum requiruntur duo, videlicet racio et rectitudo appetitus. Cum igitur aliquid horum duorum pervertitur, actus male fit et est fugiendus. Si ergo talis perversitas venit ex parte appetitus, ut racio pratica $[s i c]$ remaneat recta, vocatur incontinencia, ut cum aliquis habet rectam extimacionem de eo quod est faciendum vel vitandum sed propter passionem appetitus in contrarium trahitur. Si vero in tantum invalescat perversitas appetitus ut racioni dominetur et racio sequatur id in quo appetitus corruptus inclinat sicut principium quoddam extimans illud ut finem et optimum,

\footnotetext{
${ }^{28}$ Según Cartagena, resulta más nocivo el gusto por los singularia o delectabilia particularia, ya que somete la voluntad (Mem. I 28, ed. cit., pp. 94-95: «Et ideo summe nocivum est in viciis intemperancie immorari in cogitacione per quam homo ad singularia descendit, quia ista alliciunt voluntatem et inclinant eam ad intemperanciam; nam omnes secundum universalem consideracionem abhorrent intemperanciam, sed intemperati in particularibus sequuntur actus ejus. Qui ergo temperatus esse desiderat a cogitacione particularium delectabilium toto posse abstinere laboret»); una interpretación favorable de la concupiscencia particular, entendida como no naturalis sino como 'humana' «secundum apprehensionem (cupiditas)»; en Summa Ia-IIae, q. 30, a. 3: «[...] secundae concupiscentia sunt propriae hominum, quorum proprium est excogitare aliquid ut bonum et conveniens, praeter id quod natura requirit. Unde et in I Rhetoric., philosophus dicit primas concupiscentias esse irrationales, secundas vero cum ratione ( $c f r$. 1370a18-19). Et quia diversi diversimode ratiocinantur, ideo etiam secundae dicuntur, in III Ethic., propriae et appositae, scilicet supra naturales». Por lo demás, la incontinencia podía producirse, en términos aristotélicos, por un exceso en ambas clases de conscupiscencia (EN 1118b21-27).
} 
et operetur perversa ex eleccione, talis disposicio vocatur malicia. Est tamen ulterius considerandum quod perversitas in unaquaque re venit ex eo quod corrumpitur contemperancia debita illius rei, sicut egritudo corporalis in homine venit ex eo quod corrumpitur humorum debita armonia. Similiter perversitas appetitus que interdum racionem pervertit consistit in hoc quod corrumpitur commensuracio affeccionum humanarum; [...].

Al margen de este tipo de observaciones fisiológicas, son muy escasas -y también sobrevenidas- las referencias a la fisiognomía en la obra de Cartagena que aquí analizamos especialmente, ya sea mediante el recurso al concepto de complexio (I 30, p. 96-97: «Quando vero in tantum progreditur perversitas et corrumpitur contemperancia humanarum affeccionum ita quod progrediatur ultra limites humane vite in similitudinem affeccionum alicujus bestie, ut puta leonis, ursi, aut porci, vocatur bestialitas, sicut si ex parte corporis complexio alicujus hominis mutaretur in complexionem leoninam aut porcinam»; cfr. Sent. VII 1, 5), concepto que Cartagena volverá a emplear en su glosa de la epístola sobre las artes liberales de Séneca $^{29}$, o al de naturalis aptitudo (II 14, p. 130, en referencia a la vigésima de las propiedades que caracterizan al magnánimo; cfr. Sent. IV 10, 24):

Vicesima est quod motus corporalis magnanimi videtur esse lentus et vox ejus gravis et loquucio ejus stabilis, id est tarda. [...] acuitas vero vocis et velocitas loquucionis accidunt propter contencionem. Patet ergo quod ipsa affeccio magnanimi requirit gravitatem vocis et tarditatem loquucionis et motus, et hoc provenit ex eo [expresado in praedicamentis, según apunta Tomás de Aquino] quia quando aliquis inclinatur naturaliter ad aliquam passionem, ut pote ad verecundiam, opportet et eum naturaliter habere talem colorem qui competat verecundie; unde si quis habet naturalem aptitudinem ad magnanimitatem, consequens est eciam quod habeat naturalem disposicionem ad ista accidentia que diximus.

\footnotetext{
${ }^{29}$ Valero Moreno, «Las Artes liberales», ed. cit., pp. 198-199: «Ca como la ánima razonable sea substançia non corporal e las estrellas cosa corporal, e lo corporal non puede imprimir en lo incorporal, non se puede dezir que costelaçión alguna es bastante a mover la voluntat humana. E aunque algo puede fazer en las inclinaçiones que se mueven por la conplissión, como veemos que unos omnes se inclinan más a unas cosas que a otras, así buenas como malas por la disposiçión de su complissión, pero siempre queda la voluntat señora e solo Dios la puede mover e non criatura alguna. [...] quanto omne es más allegado a Dios tanto menos le pueden dañar las costelaçiones, e quanto más se arriedra de Dios tanto más daño pueden fazer en él las influençias de las estrellas, porque en llegándose al poderío de la causa primera, que es Dios, çesa el poderío de las causas segundas e medianas, que son los cuerpos çelestiales, o demás desto el que se allega a Dios refrena sus inclinactiones e guíase por sus santos mandamientos e por la razón, e con esto va de fuera el poderío de las estrellas. E assí podemos entender aquel común dicho que muchas vezes se dize, e es este: el varón sabidor señor será de las estrellas» (cfr. Libro de buen amor, estr. 148, y tantos otros lugares).
} 
Cabe comparar Mem. I 9, ed. cit., p. 62: «Simile in virtute temperancie: in quantum enim homo abstinendo a concupiscenciis pravis quietat se ipsum et disponit bene appetitus suos, dicitur temperatus»; Duod. IV 17, ed. cit., p. 440 y IV 22, p. 456 (a propósito del manido «fortiorem esse qui se ipsum expugnat expugnatore urbium» con base en Prov. 16, 32).

\section{El imperio del tacto: cibi y venerea}

La declaración aristotélica acerca de la preferencia humana hacia los placeres corporales, en detrimento de los espirituales, fue aducida con frecuencia por Cartagena ${ }^{30}$. Templanza y continencia vienen determinadas sobre todo por el sentido del tacto (EN 1118a23-26, Sent. II 8, 7: «temperantia autem est non circa quamlibet refrenationem, sed solum in concupiscentiis delectationis tactus», Mem. I 25, p. 90: «Sed solum consistit temperancia et intemperancia circa delectacionem tactus que versatur in illis corporis partibus quas natura concessit ad usum ciborum et venereorum»), el más compartido de los sentidos (sensus communissimus omnium: cfr. EN 1118a23-26) y que el hombre tiene en común con los demás animales, lo que hace de la falta de templanza algo especialmente vergonzoso (ibid.: «vicia intemperancie habent maximam turpitudinem et per ea homo multum infamatur et vituperatur quia assimilatur bestiiis ${ }^{31} \gg$; respuesta a Bruni de c. 1430-1434 [T. González Rolán, A. Moreno y P. Saquero Suárez, ed. cit., p. 250, 11. 702-704]: «[...] oblectamenta $[\ldots]$ quae communissima sunt et in quibus pecudibus participamus, quos $[\mathrm{sic}]$ temperantiae frenum dirigere debet, $[\ldots] \gg)$. Entendiendo,

${ }^{30} C f r$. María Morrás, «Una cuestión disputada: viejas y nuevas formas en el siglo xv. A propósito de un opúsculo inédito de Rodrigo Sánchez de Arévalo y Alfonso de Cartagena», en Atalaya, 7 (1996), pp. 63-102, en p. 90, n. 109; así en el prólogo al De los ofiçios de 1422 (ed. de María Morrás, Alonso de Cartagena, Libros de Tulio: De senetute. De los ofiçios, Alcalá de Henares, Universidad de Alcalá, 1996, p. 202, 11. 30-32: «Onde el Philósofo dize que los deleites corporales, por ser más sentidos e conosçidos por todos los omes, usurparon para sí el nombre de la deleitaçión»; cfr. EN 1153b33-1154a1, tr. Grosseteste recogn.: «Set et assumpserunt nominis hereditatem corporales delectaciones propter et pluries inclinare in ipsas, et omnes participare ipsas; propter solas igitur cognitas esse, has solas existimant esse»), en $D e$ la vida bienaventurada (Esc. N.II.6, f. 131v) o en la Quaestio Ortolana de c. 1443 (II 5, Morrás, «Una cuestión disputada...», art. cit., p. 90: «Nam ut iuxta Aristotelem loquar, 'populus ni[1] delectabile, nisi corporeum putat, ideo delectacionis nomen uoluptatis corpore sibi usurparunt'»).

${ }^{31}$ La vista era el sentido humano más estimado por Aristóteles (Metaph. 980a26-27); el tacto era, en cierto modo, su opuesto (por mucho que la visión también entrañe una forma de "contacto») y de naturaleza dolosa (Mem. I 32, p. 102, a propósito de la engañosa Venus Cyprigena); el gusto era una mera manifestación del tacto: Mem. I 25, p. 90: «et in hoc non multum delectantur intemperati, sed tota delectacio eorum consistit in usu quarundam rerum delectabilium, ut in sumpcione ciborum et potuum et usu venereorum, que pertinent ad tactum, in gustu vero non nisi in quantum ordinatur ad tactum, sicut de aliis sensibus dicebamus»; Quaest. Ortol. § 30, p. 101: «Tactus enim, cuius species quedam gustus est, terre, uisus aque, auditus aeri, odoratus igni attribuuntur». 
como era común, que la noción de «alimento» aludía tanto al seco (cibus) como al húmedo (potus), el in cibis, potibus et venereis habitual (por ejemplo en $E N 1118 \mathrm{a} 31^{32}$ ) podía sustituirse por una fórmula reducida (ya presente por ejemplo en EN 1147b26-28), frecuente en Alberto Magno ${ }^{33}$ o Tomás de Aquino (por ejemplo en Sent. III 14, 1: «[...] temperantia, quae est circa passiones respicientes ea quibus humana vita conservatur, scilicet cibos et venerea $\left.{ }^{34} \gg\right)$ y a la que Cartagena recurrirá también en otros pasajes del Memoriale (I 24, p. 87: «[...] temperancia est circa delectaciones et tristicias, que pertinent ad partem concupiscibilem, in quibus omnibus communicamus cum brutis, nam animalia bruta timent mortem et gaudent delectacione ciborum et venereorum»; frente a I 26, p. 94: «[...] delectabilia ciborum et potuum et aliorum hujusmodi in quibus intemperancia consistit occurrunt multociens in vita humana, $[\ldots] \gg)$. La misma dualidad esencial se halla implícita en otros lugares de su obra, ya con cierto alejamiento del referente aristotélico:

Otro fin mejor. Quiere dezir que el omne temprado e virtuoso non fuye de todos los deleites, ca si assí lo fiziesse non sería virtuoso, ante sería insensibile, mas usa de algunas delectaçiones non a fin de otra cosa, mas a fin de se

${ }^{32}$ Retomado por ejemplo por Pedro de Osma en su comentario a la $E N$ de $c$. 1460, ed. de José Labajos Alonso, Pedro de Osma, Comentario a la Ética de Aristóteles, Salamanca, Universidad Pontificia, 1996, p. 315: «totum fit per tactus in cibis et potibus et venereis»; p. 318: «cibi et potus, lecti, coitus et huiusmodi»; «comer e bever e en los actos venéreos» dirá el anónimo Compendio de la ética nicomaquea, ed., intr. y notas de Salvador Cuenca Almenar, Zaragoza, Prensas Universitarias de Zaragoza, 2017, p. 26; «mujeres, potajes y vino» apuntará en p. 157.

${ }^{33}$ Ethicorum libri, VII, tract. 1, cap. vI, p. 271 Jammy: «Adhuc autem eorum quae faciunt delectationem, quaedam sunt necessaria ad indiuidui vel speciei consistentiam: quaedam autem secundum se quidem sunt eligibilia vel habentia ius quare eligantur, aliquando tamen superabundantia in his vituperabilis est. Verbi gratia ea enim quae necessaria sunt, corporaliter delectantia sunt secundum tactum, verbi gratia ut talia quae sunt circa cibum et venereorum usum, sine quibus conservatio speciei non est»; cfr. Summa: IIa-IIae, q. 141 a. 4: «[...] Maxime autem naturales animalibus sunt operationes quibus conservatur natura individui per cibum et potum, et natura speciei per coniunctionem maris et feminae. Et ideo circa delectationes ciborum et potuum, et circa delectationes venereorum, est proprie temperantia. Huiusmodi autem delectationes consequuntur sensum tactus. Unde relinquitur quod temperantia sit circa delectationes tactus», siempre en la senda del propio texto bíblico (Ecclesiasticus [=Sir. 19, 2: «vinum et mulieres apostatare faciunt sapientes et arguent sensatos»).

${ }^{34}$ Cfr., por ejemplo, Contra gentiles, lib. 3 cap. 127 n. 7: «Quia vero usus ciborum et venereorum non est secundum se illicitus, sed solum secundum quod exit ab ordine rationis illicitus esse potest»; Summa, Ia, q. 114 a. 3: «[...] etiam si Diabolus non esset, homines haberent appetitum ciborum et venereorum et huiusmodi; circa quae multa inordinatio contingit, nisi per rationem talis appetitus refraenetur; et maxime, supposita corruptione naturae. Refraenare autem et ordinare huiusmodi appetitum, subiacet libero arbitrio»; IaIIae, q. 60, a. 5: «Sic igitur si consideretur aliquod bonum, si quidem sit per sensum tactus apprehensum, et ad consistentiam humanae vitae pertinens in individuo vel in specie, sicut sunt delectabilia ciborum et venereorum, erit pertinens ad virtutem temperantiae. Delectationes autem aliorum sensuum, cum non sint vehementes, non praestant aliquam difficultatem rationi»; etc. Para una cronología de las opiniones del dominico $c f r$. Andrea A. Robiglio, L'impossibile volere: Tommaso d'Aquino, i tomisti e la volontà, Milán, Vita e pensiero, 2002, pp. 123-152 («Il confronto con la nozione di 'incontinentia'»). 
delectar por otra fin mejor alcançamos buenas viandas, non por la gula, mas por conservar nuestra salut. E usa con su muger legítima en tiempos devidos, non por desseo de la delectaçión, mas por aver fijos que sirvan a Dios e ayuden a la república ${ }^{35}$.

Expresiones similares se documentan en el Duodenarium (IV 17, p. 440: «Nam si gule aut veneri indulgere vult, num hoc nedum infimorum hominum, set et pecudum comune est?»; cfr. Juan de Salisbury, Policr. VIII 11, 46, Mem. I 32, p. 102: «incontinentem libidinis vel gule»), así como en la Quaestio Ortolana de c. 1443, con tono casi humorístico:

[...] nam illud profecto prandium scolasticis uiris congruum, illam cenam ecclesiasticis personis dignam edixerim, in quibus ciborum corporalium moderata refectio sumitur et ingeniorum rubigo honesta di[s]ceptacione scolastice collu[c]tacionis emundatur, quatenus cibus corporeus non ad uoluptatem, sed ad refectionem temperate sumatur, et tota delectacio ad ea que sunt animi conuertatur! (Morrás, ed. cit., 1996, § 3, p. 88; cfr. Orac., cap. XXXIX, pp. 159-160),

Ea enim, que indiuidui atque speciei conseruacioni concernunt ad sensum tactus spectare noscuntur, nam gustus solum discernit sapores ciborum, tactus uero operatur sumptionem, quo fit ut si ex neccessitatis absolute consideracione $u[n] u m$ sensum alteri preferre uolumus. Tactus utique sensus cunctis prestaret, cum sine eo nullum animal uiuere possi. [...] Nec ob hoc iste sensus nobilior est; quinymo, ut Aristoteles uoluit, quod omni animali ac omni animalis parti communissimus est inferior aliis et excessus per eum turpior iudicatur et fame odori nocentior ( $(20$, p. 97).

Solo en el Duodenarium, a propósito de la cuarta cuestión, hemos visto que modestia y castidad son virtudes propiamente femeninas, frente a lo que ocurre con justicia y fortaleza, apunte que ya se hallaba por ejemplo en el Isagogicon de Bruni de $c$. 1424-1425, junto a otros argumentos ya mencionados en las páginas anteriores:

${ }^{35}$ Valero Moreno, «Las Artes liberales», ed. cit., p. 202; cabe recordar aquí la definición de Pedro Lombardo en torno a la necesidad del usus venereorum (Comm. in epist. Pauli, col 1589 Migne: «Incontinentiae malum est quod vir cognoscit uxorem etiam ultra necessitatem procreandi liberos, sed et ibi est nuptiarum bonum»), cuyo «abuso» resultaba, en clave medieval, no solo irracional (Tomás de Aquino, De perfect., 8: «Inter omnes autem interiores passiones maxime rationem absorbet concupiscentia carnis, et venereorum usus, [...]»), sino incluso contraproducente para la propagación de la especie (Jeremy $\mathrm{N}$. H. Lawrance, «The audience of the Libro de buen amor», en Comparative literature, 36 [1984], pp. 220237, en p. 236). 
Nam temperantia communis quiddam est, nec viri solum, verum etiam mulieris; fortitudo autem propria viri. Versatur autem temperantia circa libidines compescendas, atque, ut fortitudo a fuga nos revocat, sic temperantia ab insequendo coercet; ut, quodammodo inter se contrariae, una ad proelium cohortari, altera receptui canere videatur. Est autem temperantia circa eas voluptates, quae nobis communes sunt cum ceteris animantibus, ex quo non propriae quidem illae hominis voluptates, sed magis serviles bestialesque habentur ${ }^{36}$.

Un juicio igualmente mediatizado respecto a las mujeres se observa en el «simpliciores a natura et ingenii delicatioris» del mismo Duodenarium, IV Resp., p. 384 (cfr. Pol. 1260a12-13, EN 1150b2-3) o en la idea de que es mayor el número de mujeres virtuosas que el de hombres (IV 3, p. 392), ya que el hombre suele dedicarse a explicar la teoría de la virtud (como se afana en hacer el propio Cartagena), mientras que la mujer la pone en práctica (IV 8, p. $408^{37}$ ).

\section{Excurso acerca de la 'mantenençia' ruiziana}

Mientras la escolástica de corte aristotélico seguía cultivándose en toda Europa y nutría buena parte de la literatura clerical, Juan Ruiz escribía su Libro de buen amor (segundo cuarto del siglo XIV) y -hacia su inicio, tras el enjundioso prólogo y demás prolegómenos- su célebre estrofa 71: «Como dize Aristótiles, cosa es verdadera, / el mundo por dos cosas trabaja: la primera, / por aver mantenençia; la otra cosa era / por aver juntamiento con fenbra plazentera». Como el autor simula quizá estar recordando de sus lecciones ('la otra cosa era...'), hombres y demás animales -el 'mundo' en cuanto amenazado por la muerte y «mudable»-se esfuerzan en dos fines: el de subsistir como individuos y el de juntarse placenteramente con su hembra, consiguiendo -aunque este objetivo no se explicite- subsistir como especie, gracias al señuelo o estímulo -el clásico 'aguijón'- del mencionado placer $^{38}$.

\footnotetext{
${ }^{36}$ Montserrat Jiménez San Cristóbal, «La versión castellana del Isagogicon moralis disciplinae de Leonardo Bruni conservada en el incunable 1.704 de la Biblioteca Nacional de Madrid», en Cuadernos de Filología Clásica. Estudios Latinos, 22 (2002), pp. 87-175, en XIII, p. 154; los pasajes aludidos del Duod. en pp. 86, 89, 389, 390, 393-395.

${ }^{37}$ Lo que concuerda con el hecho de que, como recordará el Compendio, p. 153, se da «delectación venérea en hombres muy entendidos».

${ }^{38}$ No compartimos la opinión según la cual 'plazentera' remitiría al ámbito del alma intelectiva (Carlos Heusch, «'Por aver juntamiento con fenbra plazentera': el astuto naturalismo amatorio de Juan Ruiz», en El Libro de buen amor de Juan Ruiz, Archiprêtre de Hita, coord. de Id., París, Ellipses, 2005, pp. 129-142, en p. 136) y consideramos preferible el «segundo nivel» en el que Francisco Rico integró la alusión («"Por aver mantenencia”. El aristotelismo heterodoxo en el Libro de buen amor», en Estudios de literatura y otras cosas, Madrid, Destino, 2002, pp. 55-91 [= Homenaje a José Antonio Maravall, Madrid,
} 
Que el término 'mantenençia' no significa en nuestro pasaje «alimento», sino «conservación» (o sea, la unión de alimentación y generación, como corresponde al alma nutritiva de Aristóteles) es tesis que Rico mantuvo en su sugerente interpretación del pasaje $\mathrm{e}^{39}$, vertebrada a la luz de un revelador texto de la Summa (Ia-IIae q. 94 a. 2) ${ }^{40}$. El alma nutritiva inclúa, ciertamente,

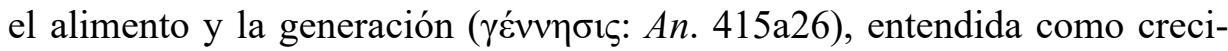
miento o incluso reproducción ${ }^{41}$; los $\dot{\alpha} \varphi \rho o \delta i ́ \sigma 1 \alpha$ (los venerea de, por ejemplo, EN 1118a31) pertenecerían al segundo nivel de la scala naturae, el del apetito voluntario y la «sensibilidad» (a veces, por cierto, desvinculada de la reproducción, como en el caso de las relaciones homosexuales o en el de las «inconvenientes»: EN 1148b29, 1149a14-15, resp.).

En nuestra opinión es más probable que el lector medio o mayoritario del Arcipreste se limitara a identificar 'mantenençia' con el alimento ${ }^{42}$ y 'juntamiento' con la reproducción y sus preámbulos (la segunda 'cosa'). Tras el paréntesis que representa la estrofa 72 , la 73 podría muy bien referirse solo a este segundo ámbito, sin que por ello se resienta, a nuestro juicio, la «ilación del pasaje» ${ }^{43}$ : se retoma el elemento más próximo y se incide en lo que realmente constituye el tema del Libro. Es también lo que parecen sugerir los muchos lugares señalados en páginas precedentes con la habitual juntura cibi et venerea, familiar para cualquier oído de la época algo formado (y no necesariamente en la doctrina heterodoxa del París de mediados del $\mathrm{XIII}^{44}$, la que

Centro de investigaciones sociológicas, 1986, pp. 271-297; vers. revis. en El Crotalón, 2 (1985), 169198], en p. 68: «cualidad 'plazentera' que el alma sensitiva disfruta en el 'juntamiento'»); también nos parece anacrónica la interpretación de 'conpaña siempre nueva' (73c) como una especie de permanente «cambio de pareja» (pese a lo que parece sugerir el 'amiga nueva' de 167d): su significado es quizá, en el contexto, el también apuntado por Rico (ibid., p. 63): «pervivencia in esse perpetuo», la nova proles de Lucr. I 259.

${ }^{39}$ Rico, «"Por aver mantenencia”», art. cit., pp. 59, 63 y n. 12, 70.

${ }^{40}$ Apud Rico, «"Por aver mantenencia”», art. cit., p. 67: «Inest enim primo inclinatio homini ad bonum secundum naturam in qua communicat cum omnibus substantiis, prout scilicet quaelibet substantia appetit conservationem sui esse secundum suam naturam. Et secundum hanc inclinationem, pertinent ad legem naturalem ea per quae vita hominis conservatur, et contrarium impeditur. Secundo inest homini inclinatio ad aliqua magis specialia, secundum naturam in qua communicat cum ceteris animalibus. Et secundum hoc, dicuntur ea esse de lege naturali quae natura omnia animalia docuit, ut est coniunctio maris et feminae, et educatio liberorum, et similia. Tertio modo inest homini inclinatio ad bonum secundum naturam rationis, quae est sibi propria, sicut homo habet naturalem inclinationem ad hoc quod veritatem cognoscat de Deo, et ad hoc quod in societate vivat. [...]».

${ }^{41}$ Rico, «"Por aver mantenencia"», art. cit., pp. 57-58.

${ }^{42}$ Rico, «"Por aver mantenencia”», art. cit., p. 59, n. 8, a propósito de la 'mantenencia' desglosada como 'manna' y 'agua' -cibus y potus- en un texto alfonsí. Que 'mantenençia' significa lo imprescindible, la mera subsistencia o existencia, podría deducirse asimismo de 110cd («non sé quién / non cobdiçie conpaña, si solo se mantién»).

${ }^{43}$ Rico, «"Por aver mantenencia”», art. cit., p. 63, n. 12.

${ }^{44} C f r$., no obstante, Carlos Heusch, «'Por aver juntamiento con fenbra plazentera’», art. cit., p. 134. 
no consideraba la continentia como una cuasivirtud - «non est essentialiter virtus»- sino directamente como un vitium, según la tesis 168 de Tempier $^{45}$ ). Que el tercer nivel adivinado por Rico, el propio del alma discursiva, parezca restringido paradójicamente a la locura o falta de seso, a la «flaqueza de la natura humana que es en el omne, que se non puede escapar de pecado» y «que más aparejada e inclinada es al mal que al bien» (pról., 11. 57-59, 72) ${ }^{46}$, es un énfasis explicable desde la idiosincrasia del propio Libro y de su autor.

Según se ha propuesto, la declaración del Arcipreste en su estrofa 71 podría proceder de la lectura del Compendium de Geremia da Montagnone y, concretamente, de la adaptación de un lugar de la Política (1262b22-23: «Duo sunt quae maxime faciunt sollicite curare homines et diligere: proprium et dilectum $\left.[\ldots] \gg{ }^{47}\right)$. En nuestra opinión y pese a las engañosas apariencias léxicas, no existe relación conceptual alguna entre los términos empleados en ese lugar de la Política y el pasaje de Juan Ruiz, inserto en un contexto filosófico bien trabado y claramente definido por la influencia de $A n$. y $E N^{48}$. Siempre es arriesgado opinar sobre el texto -deliberadamente ambiguo- al que nos estamos refiriendo, pero creemos que las 'dos cosas' a las que se refiere el

${ }^{45}$ Cfr. Rico, «"Por aver mantenencia”», art. cit., p. 74.

${ }^{46}$ Cfr. Rico, "“Por aver mantenencia”», art. cit., pp. 65, 69 y, en relación con el Zifar, p. 79.

${ }^{47}$ María Pilar Cuartero Sancho, «La paremiología en el Libro de buen amor», en Juan Ruiz, Arcipreste de Hita, y el Libro de buen amor, al cuidado de Bienvenido Morros y Francisco Toro, Alcalá la Real, Ayuntamiento de Alcalá la Real-Centro para la Edición de los Clásicos Españoles, 2004, pp. 215-234, en pp. 229-230.

${ }^{48}$ En realidad, no nos atreveríamos a afirmar que alguna de las demás citas aristotélicas del Libro supuestamente extraídas del Compendium lo sea en realidad; secuencias tan inmediatas como «cosa dura e fuerte / es dexar la costunbre» o «la costunbre es otra natura» (166ab y c, resp.) apenas pueden autorizarse en rigor (y «consuetudo est altera natura» no es uso totalmente aislado en el periodo); que Rhet. 1362b6-7 («Omnia animalia appetunt delectationem natura») inspire $73 \mathrm{bc}$ es solo una posibilidad entre muchas otras, y que 'conpaña siempre nueva' (73c) pueda ser la irónica manifestación de «transmutare delectabile est» (Rhet. 1371a25-26; cfr. EN 1154b28, también con base en Eur., Or. 234: «Transmutacio autem omnium dulcissimum secundum poetam, propter maliciam quandam...», según la versión de Grosseteste) nos parece, como hemos apuntado, inverosímil en contenido y forma, de modo que, puestos a buscar paralelos, casi cabría acudir más bien al «una forma semper appetit multas materias» del Virgilio cordobés (ed. de Salvador Martínez, Filosofia de Virgilio de Córdoba. Aristotélico-averroista del siglo XIII, León, Universidad de León, 2016; $c f r$. Carlos Heusch, «Una posible fuente para el pensamiento ruiziano, más allá del naturalismo: el "Virgilio cordobés"», en El Libro de buen amor: texto y contextos, coord. de Guillermo Serés, Daniel Rico y Omar Sanz, Bellaterra, Universidad Autónoma de Barcelona, 2008, pp. 65-80, en p. 74; cfr., por ejemplo, Sent. Metaphys. I 10, 16); algo similar cabe decir respecto a 167ab y su derivación de Rhet. 1389a4-6 (en una estructura como la de las coplas 166-167, cuya similitud con el Archipoeta, Carm. $\mathrm{X}$, estrs. 7-8, no consideramos tan desdeñable, si bien los paralelos podrían ser abundantísimos: cfr. Sent. $\mathrm{X}$ 14, 13: «specialiter iuvenibus, qui sunt proni ad delectationes»), y así sucesivamente. Es quizá la disposición de las citas la que, hasta un cierto punto, parece sugerir un reflejo del Montagnone; pero, aunque no imposible, no resulta fácil admitir como método inventivo de Juan Ruiz una labor de taracea casi centonaria -fuera, además, del prólogo- y basada en un despojo tan aleatorio -y a veces burdo- de «latinicos» del Compendium. Era, sobre todo, una innecesaria y absurda plantilla para autor tan letraherido. 
Arcipreste con su particular primum vivere eran otras y se hallaban mencionadas, de mil maneras, en muchos de los manuales que estaban a su alcance. Naturalmente, seguirán mencionándose en otros muchos posteriores, como el Memoriale de Cartagena, I 25, p. 89 (en orden de factores inverso del tradicional: generación -base de 'derecho natural', según dirá luego en el Orac., cap. XVII, p. 95- y sustento):

Et racio hujus est quia animalia bruta reguntur solo instinctu nature; ideo non delectantur nisi in hiis que pertinent ad sustentacionem nature propter quam dati sunt illis isti sensus, et ista sunt solummodo illa que pertinent ad generacionem per quam conservatur species et pertinentia ad sustentacionem per quam conservatur individuum ${ }^{49}$,

o como, por ejemplo, el Compendio de la Ética Nicomaquea (o libro 'de monástica o ética', de $\left.c .1463-1464^{50}\right)$, con directa mención de las 'dos cosas':

Quanto a las naturales, dize que -como la natura hordene los hombres a fin de dos cosas, primero a la conservación de sí mesmo, segundariamente a la conservación de la humana especie o natura- las cosas o delectaciones que [a] aquestas fines son ordenadas, lícitamente se pueden usar si sean como deven o quando, etc. ${ }^{51}$.

\section{Conclusiones}

De acuerdo con su proceder habitual, la exposición de Cartagena en el Memoriale virtutum acerca de temperantia y continentia coincide de manera esencial y a menudo literalmente con la Sententia libri ethicorum de Tomás de Aquino, su glossator de primera referencia, con escasas aportaciones personales tendentes a simplificar o aclarar ese texto de base. El resultado, coincidente a grandes rasgos con la taxonomía tomista, resulta de una notable

\footnotetext{
${ }^{49}$ Lo que ya incluía, por cierto, el dinero, según Mem. II 5, p. 115: «natura enim inclinat ad amorem diviciarum in quantum per eas vita hominis conservatur», transcribiendo Sent. IV 5, 2. Obviamente, el pasaje no permite suponer que Alfonso de Cartagena conociera el Libro de buen amor, como en alguna ocasión, sobre la base de otro tipo de referencias literarias, parece haberse sugerido (Duodenarium, pp. 92-94).

${ }^{50}$ Cuenca, Compendio, ed. cit., p. 77; la obra se atribuyó a Cartagena en varios manuscritos (cfr. Juan Miguel Valero Moreno, «Formas del aristotelismo ético-político en la Castilla del siglo XV», en Aristotele fatto volgare: tradizione aristotelica e cultura volgare nel Rinascimento, ed. de David A. Lines y Eugenio Refini, Pisa, ETS, 2014, pp. 253-310, en p. 293).

${ }^{51}$ Para la versión catalana $c f r$. Salvador Cuenca, «L'Ética nicomaquea d'Aristòtil en un compendi català del segle XV», en Anuari de la Societat Catalana de Filosofia, 23 (2012), pp. 7-119, en p. 60. Naturalmente, de ambas servidumbres estarían liberados los resucitados, ya incorruptibles, según señaló el Aquinate, Contra gent. IV 83: «Quod in resurgentibus non erit usus ciborum neque venereorum».
} 
ortodoxia, no indaga especialmente en el concepto de inclinatio (mucho menos en el factor fisiognómico o en el del influjo astrológico) y procura conjugarse con el recurso sistemático a los conceptos de 'razón' y 'voluntad', tan esenciales para Cartagena. Algunos de los postulados expuestos en relación con las dos virtudes analizadas reaparecen con relativa frecuencia en obras posteriores del autor, ya sin el corsé escolástico que caracteriza el Memoriale y con objetivos bien distintos (incluso traductológicos, como en el caso de la respuesta a Bruni a propósito del término malitia / vitium).

Los dos tipos de concupiscencia reconocidos por Aristóteles en la Ética a Nicómaco y en la Retórica (universales o comunes a todos los hombres y particulares o propias de cada individuo) permiten plantear una cuestión muy ligada a la anterior y con la que estos interfieren: la de cómo los hombres se afanan en procurarse lo necesario para su conservación como individuos y, en virtud del placer, como especie. El tratamiento del sentido del tacto por parte de Cartagena se inserta dentro de la mencionada tradición exegética, en la que tal sentido -esencialmente vinculado a las virtudes analizadas, o a su ausencia-suele verse aludido mediante la expresión cibi et venerea.

Recibido: 16/04/2018

Aceptado: 17/07/2018 
$\cos$

Temperantia Y CONTINENTIA EN El PENSAMIENTO ARISTOTÉliCo DE Alfonso DE CARTAGena (CON UN BREVE EXCURSO ACERCA DE LA 'MANTENENÇIA' RUIZIANA)

RESUMEN: La exposición acerca de la temperantia y la continentia recogida en el Memoriale virtutum de Alfonso de Cartagena (1422) es calco en gran medida de la reflexión tomista al respecto, pero también se modula según algunas de las convicciones teóricas más persistentes en el autor, por ejemplo en lo referente al necesario predominio de la ratio y de la voluntas en la conducta; el asunto vuelve a aflorar en sus obras posteriores -en términos ya menos escolásticos- y debe inscribirse en el debate filosófico y literario propio de la época en torno a la predisposición natural del individuo hacia la virtud y el vicio.

Palabras clave: Alfonso de Cartagena. Virtudes morales. Temperantia. Continentia. Mantenençia.

\section{Temperantia and continentia in Alfonso de Cartagena's Aristotelian THOUGHT (WITH A BRIEF ADDENDUM ON RUIZIAN 'MANTENENÇIA')}

ABSTRACT: The explanation of temperantia and continentia by Alfonso de Cartagena as shown in the Memoriale virtutum of 1422 is - to a large extent-a reflection of the Thomist treatment of the subject, but also faithfully reflects some of the most persistent theoretical convictions of the author, for example in relation to the necessary predominance of ratio and voluntas in behavior; it reemerges in his later works in much less scholastic terms and belongs to the philosophical and literary debate of the time around the natural predisposition of the individual towards virtue and vice.

Keywords: Alfonso de Cartagena. Moral virtues. Temperantia. Continentia. Mantenençia. 